\title{
Growth and maturation of oocytes in vitro
}

\author{
H. M. Picton ${ }^{1}$, M. A. Danfour ${ }^{2}$, S. E. Harris ${ }^{1}$, E. L. Chambers ${ }^{1}$ \\ and J. Huntriss ${ }^{1}$
}

'Academic Unit of Paediatrics, Obstetrics and Gynaecology, School of Medicine, University of Leeds, Leeds LS2 9NS, UK; and ${ }^{2}$ IVF Unit, Misurata Teaching Hospital, Misurata, Libya

The development of technologies to grow and mature oocytes from the most abundant primordial follicles holds many attractions for clinical practice, animal production technology and research. However, despite much research attention, it has proved difficult to grow follicles from early stages to maturity in vitro, as relatively little is known about the biology of oogenesis. It is clear that throughout oocyte development in vivo, follicle cell support is fundamental to provide the germ cell with nutrients and growth regulators to ensure progression through the protracted growth phase. Conversely, the oocyte actively promotes growth and differentiation of the follicular cells. Both of these characteristics must be mimicked in vitro. Replication of the normal follicular growth span from the primordial to Graafian follicle stages and the changes in the trophic requirements of the cells, cellular interactions, morphogenesis and the sheer increase in bulk as the antrum forms present major challenges for follicle culture technology. These observations could explain why methods that have proved successful for the culture of isolated rodent follicles are unable to support the growth of larger human and ruminant follicles in vitro and are incompatible with the requirements for primordial follicle growth activation. At present, the best option available for the complete growth and maturation of oocytes in vitro is to develop an extended multistage culture strategy which will provide a complex support system that closely resembles the ovary in vivo. In an attempt to achieve this goal primordial follicle growth is first initiated and maintained to the preantral stages through the culture of thin slices of ovarian cortex. The isolation and continued culture of these preantral follicles will support antral cavity formation and the induction of differentiated function in the somatic cell compartment. Finally, after exposure to an appropriate steroid milieu in vitro it should be possible to induce nuclear and cytoplasmic maturation in the fully grown oocytes. The prospects of succeeding at each stage, and of finally producing a fertile gamete, are likely to be increased by preserving cellular interactions and the phenotype of follicle cells as these provide the physiological environment in which oocytes develop. 
Although the technology for the in vitro maturation (IVM) of fully grown oocytes has been exploited successfully in ruminants, in human assisted reproduction IVM is still experimental as the efficiency of IVM is low and only a small number of pregnancies and live births have been reported. Thus, although complete in vitro growth and maturation may be achieved eventually, immediate goals must include the optimization of methods for isolating and culturing oocytes at both ends of the size spectrum and the full evaluation of the normality of the oocytes grown for extended periods in vitro.

\section{Introduction}

The growth and maturation of oocytes in vitro from the earliest primordial follicle stage is a major technical challenge for reproductive science that, if overcome, will have many rewards. The culture of preantral and especially primordial follicles to maturity has the potential to produce large quantities of oocytes for in vitro maturation and fertilization. The relatively small size, undifferentiated status and large numbers of primordial follicles present in mammalian ovaries make them prime candidates for use in association with ovarian cryopreservation for the preservation of endangered species and the genetic manipulation of domestic species. The development of an efficient cell culture system that uses human primordial oocytes could have a profound effect on the treatment options of infertile couples by avoiding the need for intensive drug treatment and repeated egg collection as several hundred follicles at early stages could potentially be recovered in a small ovarian biopsy from young ovaries. In combination, in vitro growth (IVG) of follicles together with IVM of fully grown oocytes could be used to generate sufficient oocytes for the needs of the patient and to provide spare oocytes for donation to other women or to research. Furthermore, the combined technologies of ovarian tissue cryopreservation (Picton et al, , 2000a) and growth and maturation of oocytes in vitro could help young cancer patients to preserve their fertility through the storage of their own germ cells before aggressive chemo- or radio-therapy partially or completely destroys their follicular reserve.

The full potential of IVG and IVM of mammalian oocytes was first realized when Epigg and O'Brien (1996) demonstrated that it was possible to produce live young from murine oocytes grown from the primordial stages to maturity in vitro. Although only one live offspring was produced this early result provides evidence that the complete IVG-IVM of oocytes is possible. More recently, the concept of complete IVG-IVM of oocytes has been further supported by the work of Obata et al. (2002). These authors have demonstrated that through the combination of extended culture and micromanipulation techniques, the most primitive oocytes of the mouse fetus can differentiate into fertile mature oocytes with a high efficiency. Despite these encouraging results, progress in IVG technology is slow and much effort in needed to translate the limited success of murine IVG systems into strategies that support the complete IVG of oocytes from large animals and humans. There remains a clear need for fundamental research into the biology of mammalian oocyte growth initiation, maintenance and apoptosis for the advancement of IVG technology. In addition, an improved insight is needed into the nuclear and cytoplasmic changes that are required to produce mature metaphase II (MII) oocytes that are competent to support fertilization and embryonic development. Furthermore, technical refinements in follicle and oocyte harvesting techniques and culture methodologies are required to improve the success rates of IVG-IVM systems in all species. Before considering the technology that is required to support the complete IVG and maturation of oocytes, it is 


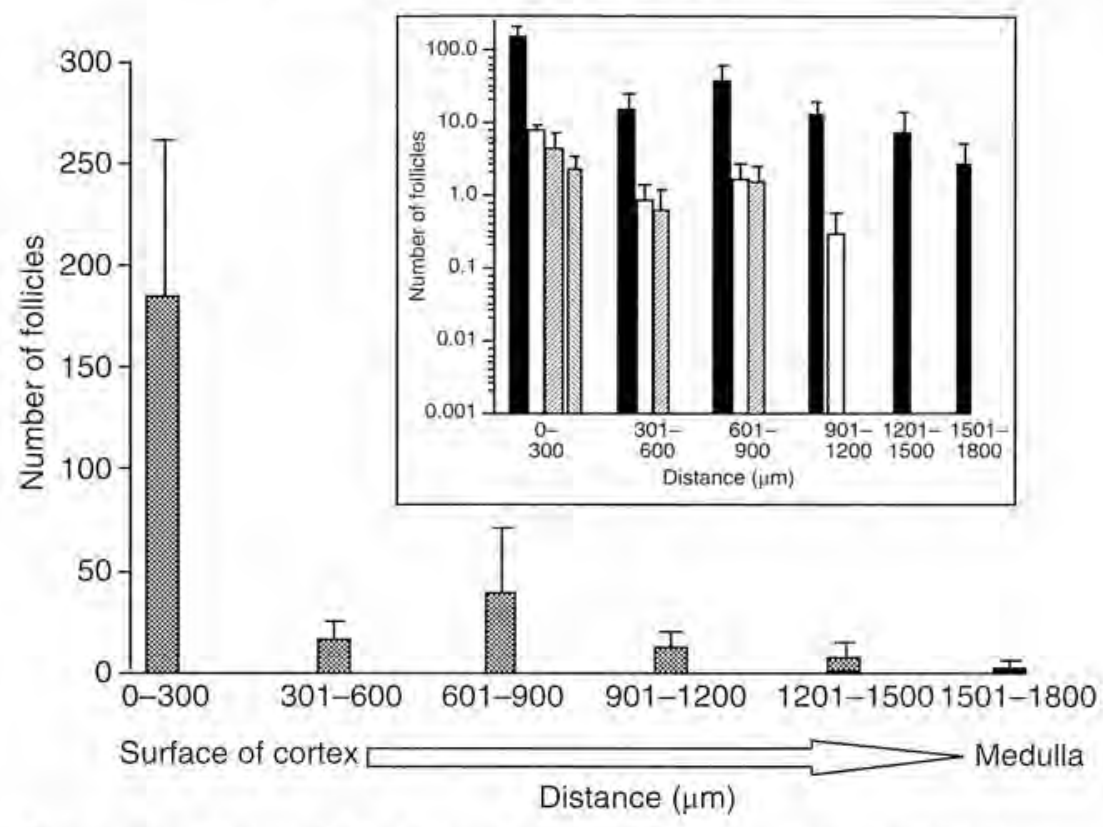

Fig. 1. Distribution of follicle populations in the transition from the outer cortex to the medullary region of the bovine ovary. Main graph: the total number of follicles of $<100 \mu \mathrm{m}$ in diameter in a $1.8 \mathrm{~mm}$ section through the surface of the bovine ovary. Insert: analysis of distribution of follicle size from primordial follicles and primary follicles of $<100 \mu \mathrm{m}$ in diameter ( $)$, secondary follicles of $100-150 \mu \mathrm{m}$ in diameter $(\square)$, late preantral follicles to the onset of antral cavity formation of 150-230 $\mu \mathrm{m}$ in diameter (שa) and early antral follicles of 230$360 \mu \mathrm{m}$ in diameter $(\mathbb{S})$ in the transition from the cortex to the medullary region of the ovary. The values presented are mean \pm SEM of the number of follicles in three $5 \mathrm{~mm} \times 5 \mathrm{~mm} \times 4 \mathrm{~mm}$ pieces of cortex collected from each of four ovaries. Please note the log scale in the insert graph.

necessary first to study the requirements for their normal growth in vivo. This review will focus on the key events in early oocyte and follicle growth that are required to support the nuclear and cytoplasmic maturation of fully grown oocytes.

\section{Early oocyte growth in vivo}

By birth, the ruminant or human ovary is endowed with hundreds of thousands of primordial follicles which will service the needs of the entire reproductive lifespan. These follicles at early stages represent the fundamental developmental unit of the mammalian ovary and their numbers will decline with advancing maternal age. Primordial follicles are composed of single partially grown oocytes surrounded by a species-specific number of flattened pre-granulosa cells (Picton, 2001). Primordial follicles are concentrated in a thin, relatively avascular, layer in the ovarian cortex beneath the tunica albuginea. In contrast, the more advanced growing follicles are always found in the cortico-medullary border which is richly vascularized (Fig. 1). The fact that primordial follicles in vivo are closely surrounded by a complex extrafollicular milieu, including ovarian stroma and theca cells at various stages of differentiation, branches of the systemic circulation, autonomic nervous system and scavenger cells indicate that many 
or perhaps all of these different types of cell may influence the initiation or maintenance of primordial follicle growth through the synthesis and secretion of nutrients, hormones or growth factors.

Among the many growth factors and peptides which are considered to act as putative paracrine-autocrine regulators of preantral follicle growth, about 15-20 have been localized to primordial, early primary and primary follicles (Picton, 2001). For primordial follicles, the candidates include growth factors such as epidermal growth factor (EGF) and its receptor, and members of the transforming growth factor $\beta$ (TGF- $\beta$ ) superfamily such as anti-Müllerian hormone, growth differentiation factor 9 (GDF-9) (McGrath et al., 1995; Dong et al., 1996) and the bone morphogenic proteins (BMPs), especially BMP-4, BMP-7 and BMP-15/GDF9B (Shimasaki et al., 1999; Otsuka et al., 2001; Braw-Tal, 2002) and other factors such as retinoblastoma protein (pRb) (Bukovsky et al., 1995). The biochemical interaction and biological antagonism of follistatin and BMP-15 may be involved in the mechanism regulating early follicle development (Otsuka et al., 2001). During activation and early follicle growth these factors may interact with c-kit which is present on the membrane of the oocyte and its ligand kit ligand, which is produced by the granulosa cells (Driancourt and Thuel, 1998). In addition, as mRNAs for the complex proliferating cell nuclear antigen (PCNA)-cyclin appear to be stimulated by EGF (Huang et al., 1993), it can be hypothesized that synthesis of EGF, which itself has a stimulatory action on granulosa cell proliferation, may induce pre-granulosa cell proliferation via PCNA synthesis in primordial follicles. Similar to EGF, mRNAs for the insulin-like growth factors (IGFs) and their respective receptors and binding proteins are known to be present in early growing follicles in a number of species (McNatty et al., 1999), indicating that the IGF system may be actively involved in both the initiation and maintenance of early follicle growth.

It is important to note that not all primordial follicles in the post-natal ovary initiate growth at the same time, so that although some factors stimulate growth initiation other factors retain some of the primordial follicles in the resting stage. For example, in the human ovary, both $\mathrm{pRb}$ and Wilms tumour suppressor gene (WT1) may be involved in the maintenance of the primordial reserve (Drummond et al., 1992; Hsu et al., 1995). The apparent inverse correlation between the proportion of growing follicles and the size of the primordial follicle store (Gosden and Telfer, 1987) has led to the suggestion that the germ cell store itself may produce a substance that inhibits growth initiation, the effect of which is directly related to the size of the primordial follicle population. However, a similar shift in the number of primordial follicles $(90 \%$ reduction) due to growth activation has been reported in short-term cultures of pieces of adult bovine ovarian cortex (Braw-Tal and Yossefi, 1997) compared with cultures of fragments of fetal ovary ( $88 \%$ reduction, Wandji et al., 1992). Overall, it would appear that the resting or growing status of primordial follicles is regulated by the complex interaction between the growth stimulators and growth inhibitors produced by the oocyte and its surrounding granulosa and stromal cells. The balance between these growth factors may also regulate the susceptibility of early follicles to apoptosis (Braw-Tal, 2002). The factors that trigger some primordial follicles to develop while others remain quiescent and the cellular source of these signals have yet to be identified.

The time period for the growth of primordial follicles to multilayer preantral stages is relatively long and varies among species (Picton, 2001). After activation, there is an increase in the size of the oocyte, although in human follicles this tends to follow hypertrophy of the pregranulosa cells and their entry into the cell cycle after a long period in G0. Antrum formation - the expansion of extracellular space in the granulosa layer - is a relatively late event in development, which takes several months in toto in primates and ruminants (Gougeon, 1996). Associated with growth initiation, there is co-ordinate expression of oocyte-specific 
genes, such as $Z p-1, Z p-2$ and $Z p-3$, the translated products of which form the extracellular membrane, the zona pellucida (Green, 1997). During growth, oocyte transcription and translation steps up markedly as the mitochondria become more vacuolated and appear 'inactive', the Golgi apparatus expands and migrates nearer the periphery and the cortical granules are formed (Picton et al., 1998). The cell cycle proteins that are required to both maintain meiotic arrest in growing oocytes and to reinitiate meiosis in mature oocytes after the preovulatory gonadotrophin surge are sequentially synthesized and accumulated during oocyte growth (Fulka et al., 1998; Picton ef al., 1998). Furthermore, there appear to be allelespecific changes in the DNA methylation of the genes associated with genomic imprinting during both gametogenesis and after fertilization during early embryo development (Mertineit et al., 1998; Young and Fairburn, 2000). Thus, the key nuclear maturation proteins and maternal mRNA species that are accumulated during oogenesis will endow the oocyte with the capacity to develop beyond the activation of the embryonic genome and pass through the transition from morula to blastocyst during preimplantation embryo development.

Throughout the lengthy pre-antral phase of folliculogenesis, the development of the oocyte is dependent on, and is concurrent with, that of the granulosa cell layers. During growth, granulosa cells become metabolically coupled with each other and also form heterologous gap junctions with the oocyte via processes passing through the developing zona pellucida to contact the oolemma (Anderson and Albertini, 1976). Thecal cells become morphologically distinguishable from the granulosa cells and the surrounding stromal tissue as follicles continue to grow, and the inner layer eventually assumes the appearance of typical steroidsecreting cells. During the later stages of preantral follicle growth and more importantly antral and preovulatory follicle development the granulosa and theca cells, undergo differentiation and become progressively more responsive to stimulation by pituitary gonadotrophins. Thus, the induction of functional granulosa and theca cell gonadotrophin receptors at the appropriate stage of follicle development (Oktay et al., 1997a; McNatty et al., 1999), together with the development of steroidogenic function in both granulosa and theca cells, can be used as functional markers of the normality of follicle development both in vivo and in vitro.

The detailed sequence of developmental events that occur during oocyte growth in vivo must be mimicked accurately in strategies designed to support oocyte and follicle growth in vitro. However, to achieve this goal, the mechanisms that regulate the growth and development of healthy oocytes and follicles in vivo must be defined clearly and their patency tested in in vitro derived cells. The development of improved molecular and proteomics strategies now make this possible. Techniques that support DNA extraction and gene analysis from small numbers of cells harvested from follicles at early stages such as those reported by Huntriss et al. (2002) in conjunction with in situ hybridization, sensitive proteomic analysis and immunohistochemical techniques will help characterize the roles of both defined genes and proteins in the regulation of normal oocyte and follicle development. The systematic application of functional genomics and IVG and IVM systems can then be used to identify the precise role of novel genes in the evolution of mature oocytes. In addition to mapping the differential expressions of known and unknown regulators of oocyte development, these techniques can be used to establish the normal expression profiles of key imprinted genes. Imprinted genes appear to be particularly vulnerable to epigenetic errors incurred as a result of altered methylation. This is relevant to IVG-IVM systems as alterations in the methylation patterns of imprinted genes, such as $\lg 2 \mathrm{r}$ and $\mathrm{H} 19$, may be induced by extended periods of culture or the inclusion of culture media additives (especially serum) (Young and Fairburn, 2000). In some instances, these alterations can lead to large offspring syndrome (Young et al., 1998; van Wagtendonk-de Leeuw et al., 2000). 


\section{Oocyte maturation in vivo}

The acquisition of developmental competence in mature oocytes depends on: (i) oocyte capacitation, which is the preparation of the oocyte during folliculogenesis for supporting early embryo development (Hyttel et al., 1997; Moor et al., 1998) and (ii) the morphological and biochemical modifications of the oocytes during maturation, which are triggered by the LH surge. Oocyte maturation in vivo is triggered by the follicular response to the preovulatory surge of gonadotrophins. These responses include (i) a shift in steroid production by granulosa cells from predominately oestrogen to a predominately progesterone environment; and (ii) production of hyaluronic acid which leads to the mucification and expansion of the cumulus granulosa cells and loss of the gap junction contact between the cumulus cells and the oocyte. These changes in the cumulus cells occur simultaneously with the nuclear and cytoplasmic maturation of the oocyte. Both the potential for nuclear maturation and oocyte cytoplasmic competence are acquired incrementally as oocytes develop (Moor et al., 1998; Picton et al., 1998). For example, the mechanisms for sperm head penetration, decondensation of chromatin and the polyspermy block are all progressively acquired during the final days of oocyte maturation before ovulation in vivo.

Meiotic maturation specifically involves development of the capacity for nuclear membrane breakdown and for progression of the oocyte from the G2 phase of the cell cycle and diplotene of the first meiotic prophase to metaphase II. Meiotic maturation is controlled by the complex interplay between the cumulus cells and the oocyte, with the participation of numerous metabolic pathways (Fulka et al., 1998). In brief, the resumption of meiosis can be explained in terms of a reduction in the concentration of CAMP and the synchronous activation and inactivation of cell cycle proteins in the ooplasm (Fulka et al., 1998; Moor et al., 1998; Picton et al., 1998). These proteins include active maturation promoting factor (MPF), mitogen-activated protein kinase, CAMP-dependent protein kinase A and the Mos oncogene product. The direct actions of MPF during germinal vesicle breakdown may involve dissolution of the nucleoli, chromosomal condensation and reorganization of the microtubular complex to form a functional spindle apparatus.

\section{Growth of follicles in vitro}

The ultimate goal for follicle culture is to be able to grow follicles from the primordial stage to maturity in vitro and to carry out IVM of oocytes with the production of viable embryos. The avascular follicular unit is relatively well-suited to a culture environment, but mounting evidence indicates that the physical and metabolic integrity of the granulosa cell-oocyte interactions must be maintained to exploit fully the developmental potential of the follicles in vitro. The mutual interdependence of oocytes and granulosa cells for survival has important practical implications for IVG strategies as both the interactions of granulosa cells and their differentiated status can be profoundly affected by components in the culture environment. For example, inclusion of FSH in the culture medium stimulates glucose utilization, oestradiol production, follicle enlargement and increased granulosa cell density and antrum formation in mouse follicles (Boland and Gosden, 1994; Boland et al., 1994; Spears et al., 1998). Although the inclusion of serum in this culture system was mandatory for follicular growth and survival, presumably by contributing hormones, nutrients and growth and attachment factors (including collagen and fibronectin), in many cases serum may also exert inhibitory effects on the follicular phenotype of the granulosa cells by inducing luteinization. Typically, rat, ruminant and human granulosa cells cultured in the presence of serum or extracellular matrix proteins (Furman et al., 1986; Amsterdam and Rotmensch, 1987) rapidly proliferate 
to form epitheloid monolayers. For the long-term IVG protocols for the follicles from large animals this remodelling may lead to the loss of granulosa-oocyte contacts and extrusion of the oocyte.

\section{Culture of primordial follicles}

Despite extensive trials, the culture of isolated primordial and primary follicles has proved extremely difficult (Hovatta et al., 1999; Picton et al., 1999b). Enzyme-isolated primordial and primary follicles rapidly lose their three-dimensional structure in both the serum-based culture environments developed to support the growth of whole mouse follicles or oocytegranulosa cell complexes (Eppig et al., 1992; Spears et al., 1994; Cortvrindt et al., 1996) and the serum-free systems that support antral cavity formation in the follicles of large animals and humans (Newton et al., 1999; Picton et al., 1999b). Naked, immature oocytes may remain viable for a few days in a nutrient culture medium but as only follicle cells can provide the specific, and as yet undefined, factors needed for oocyte growth, oocyte degeneration rapidly follows loss of follicular integrity. It is also possible that the lack of influence from pre-theca and extrafollicular cells contributes to the demise of isolated primordial follicles. For cultivation of these very early follicles to the stage when antral cavity formation can occur (which is at approximately $230-350 \mu \mathrm{m}$ in ruminant and human follicles), it is important to prevent the pre-granulosa cells from migrating away from the oocyte and so breaking the metabolic link between the two cellular compartments.

An alternative strategy to the culture of isolated primordial follicles is to grow the very early stages in situ in thin slices $(75-100 \mu \mathrm{m})$ of ovarian cortex. The simple technique of cortical strip culture: (i) avoids the damage caused by the follicle harvesting procedure; (ii) provides a complex support system which more closely resembles the ovary in vivo as the follicles remain both intact and in contact with the surrounding stromal cells; and (iii) provides the local biochemical control pathways that trigger the initiation of follicle growth. However, cultured cortical tissue must be sufficiently thin to avoid limitations of gas and metabolite diffusion and must preserve an appropriate nutrient and paracrine environment for triggering and maintaining follicle growth. Necrosis of tissue owing to inadequate oxygenation will become a problem if tissue pieces are too large. When cortical slices are cultivated in culture inserts with or without extracellular matrix and large amounts of serum (Hovatta et al., 1999; Wright et al., 1999) or in a species-specific serum free medium (Newton et al., 1999; Picton et al., 1999b), many follicles remain viable and are morphologically normal after 1-2 weeks of culture. Furthermore, PCNA staining has indicated that some of the primordial follicles had started to grow and had reached the primary stage (Picton et al., 1999b). In some cases, initiation of primordial follicle growth appears to be unregulated in this system, as a higher percentage of primordial follicles was found to be activated compared with controls in cultured pieces of bovine cortex (Wandji et al., 1996b) than in whole bovine fetal ovaries (Mhawi et al., 1991). Alternatively, cortical tissue can be grafted beneath the chorioallantoic membrane of chick embryos to study the activation of primordial follicle growth (Cushman et al., 2002). Cortical strip cultures for primordial and primary follicles could therefore be used to grow follicles to preantral stages in situ when they can be harvested for continued growth in isolated culture. In support of this contention, murine follicles at early stages have been grown in organ culture to a stage at which the granulosa-oocyte complexes could be enzymatically or mechanically isolated and transferred to a fresh environment for continued growth (Eppig and O'Brien, 1996; Obata et al., 2002). Alternatively, cultured explants can be xenografted to host animals to complete development in vivo. 


\section{Culture of preantral follicles}

To date, culture of preantral follicles has been used most successfully with mouse follicles (for a review, see Gosden et al., 2002); however, the growth characteristics of the follicles are highly dependent on the culture system used. In general, oocytes from preantral follicles of infant mice are sufficiently mature for IVF after 10-13 days of growth in vitro in a defined media. When preantral granulosa-oocyte complexes are cultured on collagen impregnated membranes using the approach of Eppig et al. (1992) limited cell attachment to the membrane occurs and the complexes extend a stalk of granulosa cells containing an oocyte. Alternatively, intact follicles can be grown successfully in two dimensions on a plastic substrate in the presence of serum (Cortvrindt et al., 1996). Although follicular shape and architecture are altered using this method, the follicular cell types remain in contact; antral-like cavities are formed; and responsiveness to gonadotrophin stimulation is preserved. Consequently up to $40 \%$ of the cultured follicles produce oocytes that can be induced to undergo IVM to MII after 2 weeks of culture with FSH and acute exposure to stimulation with hCG. Alternatively, using a porous membrane or microdrops of medium under mineral oil, it is possible to grow intact mouse follicles of mid-preantral size to the Graafian stage in about 6 days. The follicles have normal morphology and steroid production (Nayudu and Osborn, 1992; Boland et al., 1994; Spears et al., 1994; Hartshorne et al., 1994) and up to $80 \%$ of the follicles will ovulate in vitro in response to hCG (Rose et al., 1999).

In recent years it has also proved possible to maintain the three-dimensional structure of preantral ruminant (Newton et al., 1999; Gutierrez et al., 2000) and human (Picton et al., 1999b) follicles grown in vitro using a serum-free culture system developed for ruminant (Campbell et al., 1996; Gutierrez et al., 1997) and pig granulosa cells (Picton et al., 1999a). Use of this species-specific approach allows both induction and maintenance of oestradiol production by long-term cultures of granulosa cells, which remain exquisitely sensitive to physiological concentrations of gonadotrophins and growth factors. In this culture system, cultured granulosa cells form distinct clumps of rounded cells, which closely resemble the morphology of the type of cell in vivo (Chang et al., 1977). When applied to IVG strategies for preantral follicles this serum-free culture approach serves to maintain the extensive network of gap junctions between granulosa cells and also between the cumulus cells and the oocyte. This procedure maintains follicle integrity in vitro, allows antral cavity formation and follicle growth and supports the induction of steroidogenic function in the cultured follicles.

Irrespective of species, it is clear that the approach used to extract preantral follicles from the ovary can profoundly affect their IVG potential. Various methods have been developed to isolate and culture preantral follicles. Mechanical isolation is relatively easy for soft tissues, such as fetal ovarian samples, which contain large numbers of small follicles. This method has been used successfully by a number of workers for mouse follicles (for a review, see Hartshorne, 1997). The main advantage of this approach is that the theca layer remains intact and basement membrane damage is avoided. Many of the manually isolated follicles retain their characteristic structure when cultured individually in vitro, as the theca layer is important in sustaining spherical development in the absence of a supporting gel, and it may also promote antrum formation (Qvist et al., 1990; Gosden et al., 1993). The observation that murine preantral follicles cultured without theca cells (that is follicles harvested by enzyme digestion) have retarded growth rates compared with theca-enclosed follicles (that is follicles harvested by mechanical isolation) (Boland and Gosden, 1994) supports the concept that the theca cells have biochemical effects on oocyte growth and development in vitro, which are mediated via the granulosa cells (Kotsuji et al., 1994; Richard and Sirard, 1996). 
In tough tissues, such as human, ovine or bovine ovarian cortex, it is technically difficult to isolate mechanically preantral follicles from the surrounding connective tissue (Figueiredo et al, 1993; Roy and Treacy, 1993). Enzymatic methods are used routinely to aid follicle harvest to alleviate this problem. Partial disaggregation of the tissue with proteolytic enzymes, such as collagenase type $1 \mathrm{a}$ and DNAse I, softens the tissue so that the follicles at early stages can be detected and detached from the surrounding stromal tissue using fine needles. Roy and Treacy (1993) demonstrated that exposure to enzyme (2472 units of collagenase 1A) for $1 \mathrm{~h}$ at $37^{\circ} \mathrm{C}$ followed by $36 \mathrm{~h}$ at $4^{\circ} \mathrm{C}$ allowed large numbers of intact preantral human follicles to be isolated per ovary, and that this long exposure to collagenase did not damage follicular structure as assessed by gross microscopic examination of follicle morphology. In contrast, short exposure with the same or even a threefold higher concentration of collagenase was not effective. Wandji et al. (1996a) have also reported the successful isolation of morphologically normal fetal bovine preantral follicles. These workers collected 30-50 preantral follicles of $60-179 \mu \mathrm{m}$ in diameter per ovary. Although it is possible to harvest large numbers of follicles by enzymatic digestion, the method is very slow, removes the theca cell layer and causes basement membrane damage. Nonetheless, significant progress has been made by a number of groups using this method of tissue harvesting with different culture environments. In our studies with a physiological serum-free culture media, antral cavity formation, oocyte growth and the activity of the key steroidogenic enzyme aromatase can be induced in approximately $20 \%$ of sheep preantral follicles cultured over 30 days in vitro after enzymatic isolation (Newton et al., 1999). In this study we attributed the observation that in vitro follicle growth did not proceed beyond $1.1 \mathrm{~mm}$ in diameter to the lack of the thecal cell layer. Furthermore, the fact that $60 \%$ of the oocyte granulosa cell complexes extruded their oocytes, had necrotic oocytes or had lost their three-dimensional spherical structure and collapsed on to the culture plate after 5 days of culture occurred because of basement membrane damage and/or lack of theca cells incurred by the enzymatic digestion method of Newton et al. (1999).

Although it is relatively easy to harvest theca-free follicles by enzymatic isolation, for ruminants and humans it is more difficult to harvest intact theca-enclosed preantral follicles because of the tough fibrous matrix in which the follicles are embedded. However, preantral follicles can be mechanically isolated without the use of enzymes by either preparing thin slices of ovarian cortex using a scalpel before manual dissection of follicles is attempted, or by passing small pieces of ovarian cortex through a sieve (Danfour et al,, 1999a). After cortical slice preparation, the location of small intact follicles can be ascertained in advance by transillumination of the tissue slices (Gosden et al., 1993) or staining using viability stains that do not compromise subsequent follicle development in vitro (Chambers et al., 2002). Alternatively, bovine preantral follicles have been harvested by cutting the ovary into small pieces and the follicles loosened from the connective tissue by repeated pipetting (Figueiredo et al., 1993). In contrast to the observations from the murine studies reported above, a direct comparison of the growth rates of theca-free ovine follicles harvested by enzymatic digestion and needle isolation with theca-enclosed ovine follicle harvested by mechanical isolation alone indicates that the in vitro growth rates and antral cavity formation of thecafree follicles are greater than the growth rates of theca-enclosed follicles (Fig. 2). In the theca-enclosed follicles, antral status was achieved in vitro by the oocyte and granulosa cell compartments breaking through the basement membrane and theca cells layers which remain tightly associated (Fig. 3). This observation serves to highlight both the potential speciesspecific differences in the response of follicles of different sizes to the culture environment and the differential growth rates of rodent and ruminant follicles. The requirement for theca cell interactions in optimizing ruminant and human preantral-antral follicle culture systems may perhaps be overcome through the improvement of the culture media or the co-culture of 

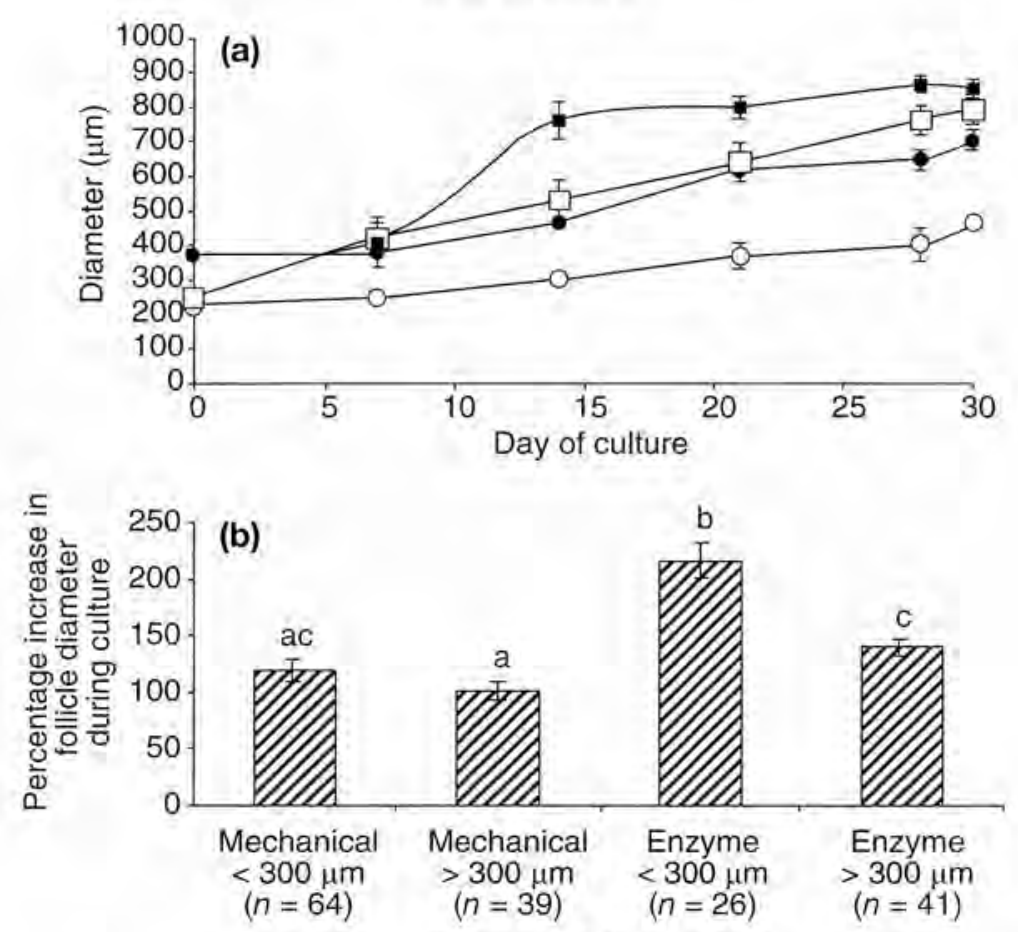

Follicle isolation method

Fig. 2. Comparison of the growth rates of ovine follicles in vitro. (a) Comparison of the growth rates of theca-free (squares) and theca-enclosed (circles) preantral follicles of $<300 \mu \mathrm{m}$ diameter (open symbols) and early antral follicles of $>300 \mu \mathrm{m}$ (closed symbols) harvested by either enzyme digestion or mechanical isolation, respectively. (b) Increase in diameter of follicles harvested by enzyme digestion or mechanical isolation, respectively, after 30 days of growth in vitro. The values plotted are means \pm SEM for the number of follicles shown. Columns with different letters are significantly different $(P<0.05)$.

enzymatically isolated preantral follicles with theca cell monolayers. The optimal method for the isolation and culture of viable preantral follicles from large animal species and humans remains to be elucidated.

On the basis of these observations, the complete IVG of ruminant and human follicles is most likely to be achieved through the use of a multistage culture strategy which is compatible with the requirements for: (i) the initiation and maintenance of primordial follicle growth; (ii) antral cavity formation; and (iii) the induction of differentiated function in follicular somatic cells to support the acquisition of cytoplasmic maturation of oocytes. Finally, the fully grown oocytes will be harvested for IVM. It is likely that the complete IVG of follicles will be achieved only when the critical determinants of follicle culture have been integrated with an improved understanding of the biology of oocyte development in vivo (Fig. 4).

\section{Maturation of oocytes in vitro}

The changes that occur during oocyte maturation in vivo must be precisely replicated during oocyte maturation in vitro. Thus, to prepare for fertilization and early embryo development, 

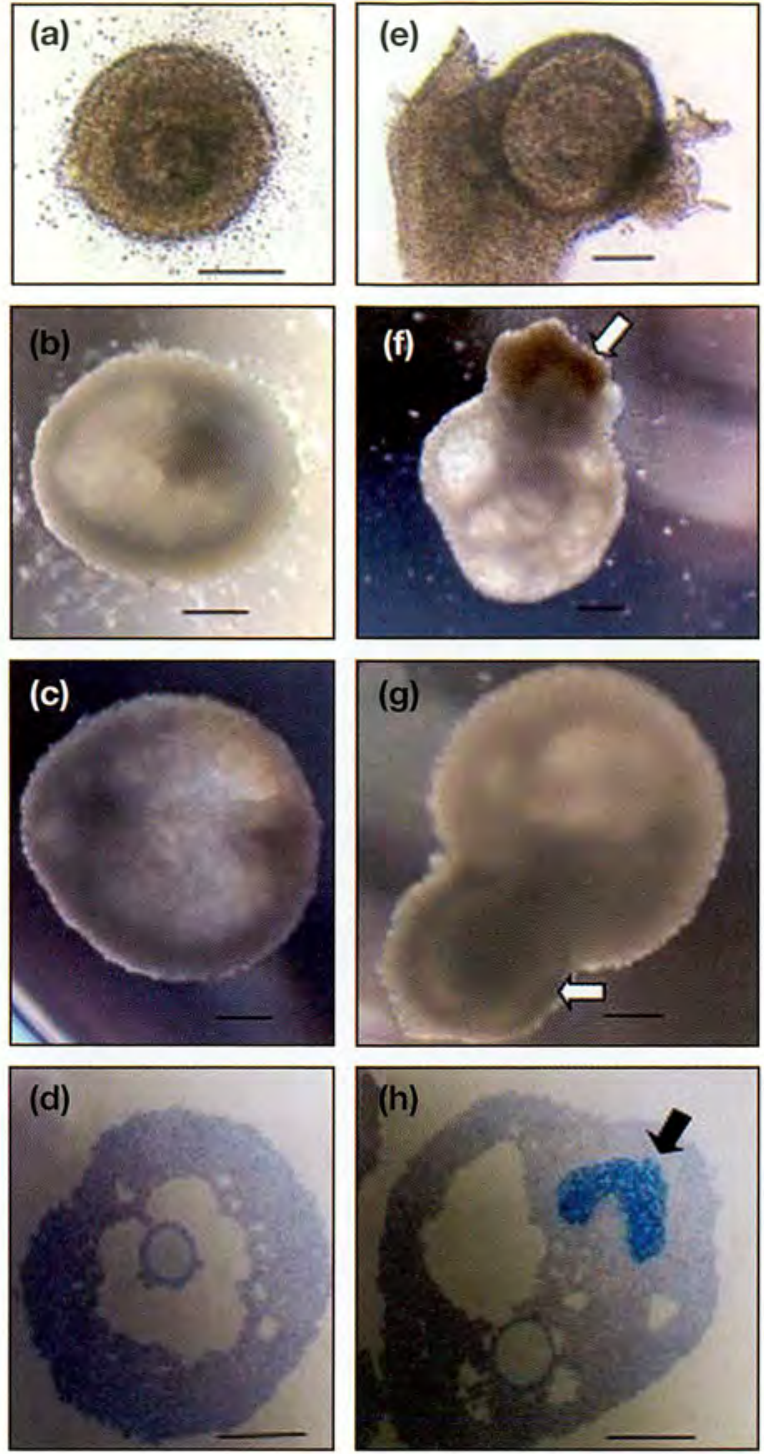

Fig. 3. Morphology of isolated preantral $(<230 \mu \mathrm{m}$ in diameter) sheep follicles grown in serum-free culture media over 30 days in vitro. (a-d) The theca-free follicles harvested by enzyme digestion at the start of culture (a) develop (b and c) antral cavities in vitro and show no evidence of the presence of the basement membrane at the end of culture (indicated by lack of staining for the presence of collagen in sections of cultured follicles) (d). (e-h) In contrast, theca-enclosed follicles collected by mechanical isolation at the start of culture (e) show evidence of antral cavity formation by outgrowth from the dense theca and stromal cells (white arrows; $f$ and $g$ ) which remain concentrated within one area as indicated by positive staining for collagen (black arrow) in follicles that have been fixed and sectioned after extended culture (h). Scale bars represent (a,e) $100 \mu \mathrm{m}$ and (b-d, f-h) $200 \mu \mathrm{m}$. 


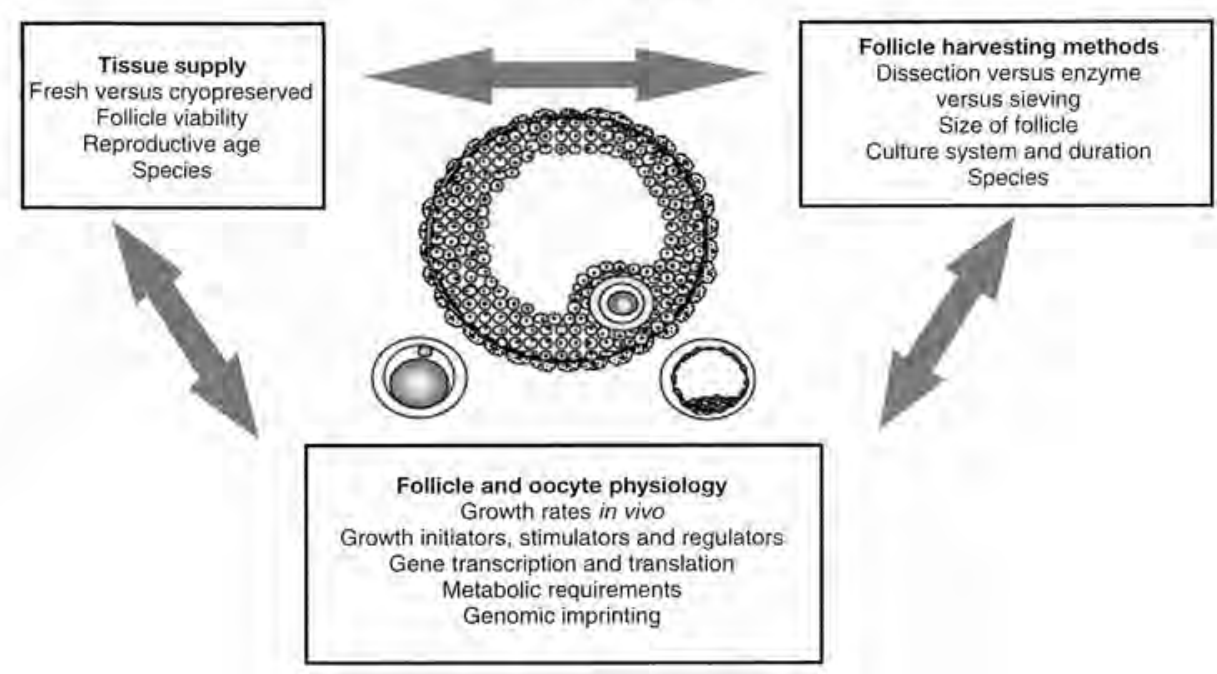

Fig. 4. Summary of the critical determinants of the success of growth and maturation systems in vitro for mammalian oocytes. The success of the culture strategy will be influenced by the endpoint selected; these can be the production of antral or Graafian follicles, metaphase II oocytes, cleavage stage embryos or blastocysts.

oocytes matured in vitro must pass through the same complex series of checkpoints of transcription and translation, DNA replication and repair, chromosome condensation and spindle formation as oocytes matured in vivo. After the harvest of full-sized, cumulus-enclosed oocytes at the germinal vesicle stage grown either in vivo or in vitro, cytoplasmic and nuclear maturation must be induced in the oocyte through a $24-48 \mathrm{~h}$ incubation in IVM culture media. Concurrently, the compacted cumulus granulosa cells that surround the oocyte must undergo a degree of mucification and expansion resembling the changes seen in these cells in vivo. Both the follicular environment in vivo and, more importantly in the context of IVG, the local environment in vitro will be important in regulating oocyte capacitation. Although it is very difficult to improve oocyte quality, as this is acquired sequentially over several months during follicle development, the IVM conditions can be adapted to improve the oocyte maturation potential. Therefore, it is not surprising that oocyte maturational competence is linked to follicle size and that the microenvironment of the oocyte immediately before nuclear and cytoplasmic maturation in vitro affects fertilization and early embryo developmental potential. The meiotic competence of oocytes from follicles of different sizes has been investigated in several species. An extensive review of the literature (Danfour, 2001) has revealed that bovine follicles of large diameter contain oocytes with higher IVM potential than that of the oocytes from small follicles such that a follicular diameter of at least $3 \mathrm{~mm}$ must be achieved in vivo before satisfactory oocyte developmental competence is attained in vitro.

Culture media components and culture conditions used for IVM can affect the meiotic regulation of oocytes (Downs and Mastropolo, 1997; Kito and Bavister, 1997). The media conventionally used for IVM consists of a balanced salt solution, oxygen, bicarbonate ions, proteins, amino acids, an energy source and various additives at $\mathrm{pH} 7.4$ (Picton, 2002). Although two reports have shown that culture additives, such as follicular fluid meiosisactivating sterol, can stimulate murine (Gröndahl et al., 2000b) and human oocyte maturation (Gröndahl et al., 2000a), in most reports, oocyte maturation is achieved in media containing up to $10-50 \%$ bovine serum or homologous human serum (Danfour, 2001; Picton, 2002). The 
serum acts as a source of albumin, which balances the osmolality and scavenges potentially harmful molecules and metal ions that can act as a source of free oxygen radicals. Serum also contains proteins, amino acids, carbohydrates, trace elements, hormones, growth factors and some as yet undefined components. However, serum-based culture systems may be undesirable on the grounds of safety and quality control for oocyte IVM. In both animals and humans, serum could be a source of transmission of pathogenic diseases, in particular viral diseases, such as HIV and hepatitis $B$ and $C$ in humans and bovine viral diarrhoea virus, which is one of the common infections in cattle. Finally, the lessons learnt from murine, bovine and ovine embryo production systems in vitro indicate that although effective, the use of serum in culture media is ill advised as it can lead to epigenetic modifications and fetal overgrowth consistent with large offspring syndrome (Young et al., 1998; Young and Fairburn, 2000; van Wagtendonk-de Leeuw et al., 2000). This condition is often associated with slightly extended gestation and an increase in post-natal mortality, due to a greater incidence of dystocia. Although there is as yet no direct evidence to indicate that large offspring syndrome occurs in humans, the possibilities of increased incidence of imprinting disorders as a result of the use of serum-based media for IVM, especially when they are used in conjunction with IVG of follicles, should not be overlooked.

An alternative and safer option for IVM is to use serum-free culture media for IVG (Newton et al., 1999; Picton et al., 1999b), IVM (Wynn et al., 1998, Danfour et al., 1999b) and embryo production (Tay et al., 1997; Gandhi et al., 2000). If the maturation media is supplemented with purified or recombinant gonadotrophins (Wynn et al., 1998; Anderiesz et al., 2000), high levels of oocyte maturation and embryo development can still be achieved in the absence of serum in both ruminants and humans. Furthermore, some reports indicate that improvement in the harvest of cells and perhaps oocyte quality can be gained by mild ovarian stimulation with FSH in vivo before oocyte collection (Schramm and Bavister, 1994; Wynn et al., 1998). With the procedure of Wynn et al. (1998), cumulus-enclosed oocytes will undergo limited cumulus expansion and progress to metaphase II within 36-40 h (human) and $24 \mathrm{~h}$ (bovine) of collection in the presence of surge concentrations of gonadotrophins. The application of this serum-free approach to the microdrop culture of individual bovine cumulus-oocyte complexes produces high levels of oocyte maturation $(65 \pm 7 \%)$ and blastocyst development $(23 \pm 7 \%$ ) (Fig. 5). With this approach oocyte quality or developmental potential appears to be maximized as embryo development is not affected by oocyte origin, method of harvest (Danfour et al., 2002) or culture medium components (Fig. 5). Furthermore, with this system, both cumulus cell coverage and particularly expansion of individual oocytes during IVM are highly predictive of subsequent blastocyst developmental potential (Danfour, 2001). Therefore, the success of IVM systems depends on a number of factors including the cumulus granulosa cell association, granulosa cell differentiation and follicle size and atresia. It is likely that the culture requirements will be even more stringent when applied to the IVM of oocytes harvested from IVG follicles.

Although serum-free culture systems have many advantages and provide the opportunity to study energy metabolism and the effects of growth factors and hormones on oocyte growth and maturation, serum-free media may have an undesirable side-effect, namely precocious cortical granule release, and the induction of premature hardening of the zona pellucida. Zona pellucida hardening occurs naturally after fertilization in oocytes from many species as a consequence of cortical granule release and so constitutes the primary block to polyspermy. If premature zona pelludica hardening occurs, the fertilization potential of oocytes is reduced (Green, 1997). Zona pellucida hardening has been shown to reduce the rate of blastocyst hatching in rhesus monkeys from $77 \%$ using serum to $25 \%$ using serum-free medium (Schramm and Bavister, 1994). Furthermore, in the mouse, inclusion of serum in 

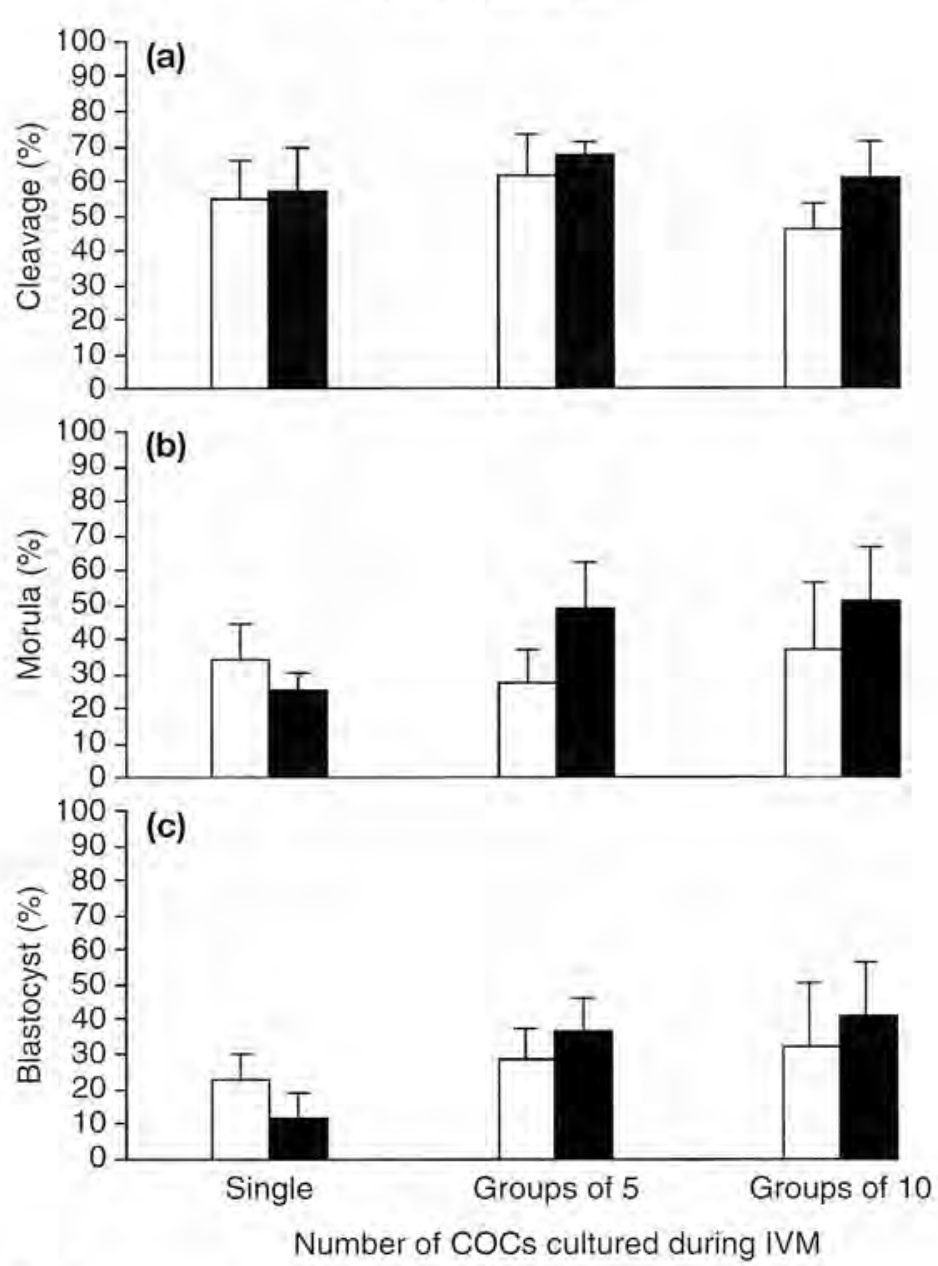

Fig. 5. Comparison of the (a) cleavage, (b) morula and (c) blastocyst production rates of bovine embryos produced after the in vitro maturation of oocytes cultured individually or in groups of five or ten in microdrops of serum-free media ( $\square$ ) or media containing serum (a). Values are means \pm SEM for eight repeat cultures. When culture conditions are optimized there are no significant differences between embryos derived from either culture environment. (M. A. Danfour and H. M. Picton, unpublished).

oocyte maturation medium appears to prevent premature loss of cortical granules and zona pellucida hardening (Downs et al., 1986). In contrast, mouse (De Felici and Suracusa, 1982) and rat oocytes (Zhang et al., 1991) have been found to undergo spontaneous zona pellucida hardening as indicated by increased resistance to protease digestion, when matured in vitro in serum-free medium. This process is thought to occur because fetuin, a major glycoprotein component of fetal calf serum and a protease inhibitor, is absent from serum-free media. Fetuin has been shown to inhibit hardening of the zona pellucida during IVM of mouse oocytes by preventing the proteolytic conversion of ZP2 to ZP2 f by precociously released cortical granules and so allow fertilization at frequencies equivalent to those observed in oocytes cultured in serum-based medium (Schroeder et al., 1990). However, this effect of 
fetuin may be specific to species and culture media, as Dell'Aquila et al. (1999) have reported that the addition of fetuin to serum-free medium reduced zona pellucida hardening in equine oocytes but did not improve sperm penetration during IVF. Initial concerns about the induction of precocious cortical granule release and zona pellucida hardening as a result of the exclusion of serum from the maturation media used for bovine (Danfour et al., 2002) and human oocytes (Wynn et al., 1998) appears to be unfounded as blastocyst production rates from bovine oocytes matured individually or in groups of five or ten compare favourably with the number of blastocysts produced from oocytes matured in serum-based IVM media (Fig. 5). Furthermore, measurement of hardening status of the zona pellucida by enzymatic digestion or by the detection of alterations in the electrophoretic mobility of zona pellucida proteins (Picton et al., 2000b) has confirmed that hardening of the zona pellucida does not occur in this serum-free system.

\section{Conclusion}

A culture strategy that is compatible with the initiation and maintenance of primordial follicle growth, antral cavity formation and the induction of differentiated function in vitro would represent a major advance in follicle culture technology and is a step towards the goal of complete IVG and maturation of oocytes. It is likely that the future success of IVG-IVM systems will be achieved only by improving understanding of the molecular and cell biology of follicle and oocyte development. This in turn will support the development of improved, extended culture methodologies. Until this research has been undertaken, the potential of IVG-IVM of follicles from large animals and humans remains only a distant prospect.

\section{References}

Amsterdam A and Rotmensch S (1987) Structurefunction relationships during granulosa cell differentiation Endocrine Reviews 8 309-337

Anderiesz C, Ferraretti A-P, Magli C, Fiorentino A, Fortini D, Gianaroli L, Jones GM and Trounson AO (2000) Effect of recombinant human chorionic gonadotrophins on human, bovine and murine oocyte meiosis, fertilization and embryonic development in vitro. Human Reproduction 15 1140-1148

Anderson E and Albertini DF (1976) Gap junctions between the oocyte and companion follicle cells in the mammalian ovary Journal of Cell Biology 71 680-686

Boland NI and Gosden RG (1994) Effects of epidermal growth factor on the growth and differentiation of cultured mouse ovarian follicles Journal of Reproduction and Fertility 101 369-374

Boland NI, Humpherson PG, Leese $\mathrm{HJ}$ and Gosden RG (1994) The effect of glucose metabolism on murine follicle development and steroidogenesis in vitro. Human Reproduction 9 617-623

Braw-Tal R (2002) The initiation of follicle growth: the oocyte or the somatic cells? Molecular and Cellular Endocrinology 187 11-18

Braw-Tal R and Yossefi S (1997) Studies in vivo and in vitro on the initiation of follicle growth in the bovine ovary Journal of Reproduction and Fertility $109165-$ 171
Bukovsky A, Caudle MR, Keenan JA, Wimalasena J, Foster JS and Van Meter SE (1995) Quantitative evaluation of the cell cycle-related retinoblastoma protein and localization of Thy-1 differentiation protein macrophages during follicular development and atresia, and in human corpora lutea Biology of Reproduction 52 776-792

Campbell BK, Scaramuzzi RJ and Webb R (1996) Induction and maintenance of oestradiol and im. munoreactive inhibin production with FSH by ovine granulosa cells in serum-free media Journal of Reproduction and Fertility 106 7-16

Chambers EM, Gosden RG, Miller D and Picton HM (2002) In situ identification of follicle viability and developmental potential in cryopreserved ovarian cortex Reproduction Abstract Series 2834

Chang SCS, Anderson W, Lewis JC, Ryan RJ and Kang YH (1977) The porcine ovarian follicle. II. Electron microscopic study of surface features of granulosa cells at different stages of development Biology of Reproduction 16 349-357

Cortvrindt R, Smitz I and Van Steirteghem AC (1996) In vitro maturation, fertilization and embryo development of immature oocytes from early preantral follicles from prepubertal mice in a simplified culture system Human Reproduction 11 2656-2666

Cushman RA, Wahl CM and Fortune JE (2002) Bovine cortical pieces grafted to chick embryonic 
membranes: a model for studies on the activation of primordial follicles Human Reproduction 17 48-54

Danfour MA (2001) Influence of the Environment on Mammalian Oocyte Development PhD Thesis. University of Leeds, Leeds

Danfour MA, Picton HM, Chambers EL and Gosden RG (1999a) Development of a mechanical method for isolation of intact preantral follicles from bovine ovaries. National Ovarian Workshop, Southampton

Danfour MA, Picton HM and Gosden RG (1999b) Impact of culture and cellular environment on the maturation potential of bovine oocytes in vitro. Journal of Reproduction and Fertility Abstract Series $\mathbf{2 4} 44$

Danfour MA, Coulthard $\mathrm{H}$ and Picton HM (2002) $\mathrm{lm}$ pact of oocyte maturation environment on bovine embryo development in vitro. Reproduction Abstract Series $\mathbf{2 8} 63$

de Felici M and Siracusa G (1982) Spontaneous hardening of the zona pellucida of mouse oocytes during in vitro culture Gamete Research 6 107-113

Dell'Aquila ME, Felici MD, Massari S, Maritato $F$ and Minoia P (1999) Effect of fetuin on zona pellucida hardening and fertilisability of equine oocytes matured in vitro. Biology of Reproduction 61 533-540

Dong J, Albertini D, Nishimori K, Kumar T, Lu N and Matzuk M (1996) Growth differentiation factor 9 is required during early ovarian folliculogenesis Nature 383 531-535

Downs SM and Mastropolo AM (1997) Culture condition affects meiotic regulation in cumulus-cell enclosed mouse oocytes Molecular Reproduction and Development $46551-556$

Downs SM, Schroeder AC and Eppig J) (1986) Serum maintains the fertilization of mouse oocytes matured in vitro by preventing the hardening of zona pellucida Gramete Research 15 115-122

Driancourt MA and Thuel B (1998) Control of oocyte growth and maturation by follicular cells and molecules present in follicular fluid: a review Reproduction. Nutrition and Development 38 345-362

Drummond IA, Madden SL, Rohwer-Nutter P, Bell GI, Sukhatme VP and Rauscher FJ, III (1992) Repression of the insulin-like growth factor II gene by Wilms tumor suppressor WTI Science 257 674-678

Eppig JJ and $\mathbf{O}^{\prime}$ Brien MJ (1996) development in vitro of mouse oocytes from primordial follicles Biology of Reproduction 54 197-207

Eppig JI, Wigglesworth K and O'Brien MJ (1992) Comparison of embryonic developmental competence of mouse oocytes grown with and without serum Molecular Reproduction and Development 32 33-40

Figueiredo JR, Hulshof SC, Van den Hurk R, Bevers MM, Nusgens B and Beckers JF (1993) Development of a new mechanical method for the isolation of intact preantral follicles from fetal, calf and adult bovine ovaries Theriogenology 40 789-799

Fulka J, Jr, First NL and Moor RM (1998) Nuclear and cytoplasmic determinants involved in the regulation of mammalian oocyte maturation Molecular Human Reproduction 4 41-49

Furman A, Rotmensch S, Dor I, Veter A, Mashiach S, Vlodavsky I and Amsterdam A (1986) Culture of human granulosa cells from an in vitro fertilization program: effects of extracellular matrix on morphology and cyclic adenosine $3^{\prime}, 5^{\prime}$-monoposphate production Fertility and Sterility 46 514-517

Gandhi AP, Lane M, Gardner DK and Krisher RL (2000) A single medium supports development of bovine embryos throughout maturation, fertilisation and culture Human Reproduction 15 395-401

Gosden RG and Telfer E (1987) Numbers of follicles and oocytes in mammalian ovaries and their allometric relationships Journal of Zoology 211 169-175

Gosden RG, Boland NI, Spears N, Murray AA, Chapman M, Wade JC, Zohdy NI and Brown N (1993) The biology and technology of follicular oocyte development in vitro. Reproduction Medicine Reviews 2 129-152

Gosden RG, Mullan J, Picton HM, Yin $\mathrm{H}$ and Tan SL (2002) Current perspective on primordial follicle cryopreservation and culture or reproductive medicine Human Reproduction Update 8 105-110

Gougeon A (1996) Regulation of ovarian follicular development in primates - facts and hypotheses Endocrine Reviews 17 121-155

Green DPL (1997) Three dimensional structure of the zona pelliucida Reviews of Reproduction 2 $147-156$

Gröndahl C, Hansen TH, Marky-Nielsen K, Ottesen JL and Hyttel P (2000a) Human oocyte maturation in vitro is stimulated by meiosis-activating sterol Human Reproduction 15 Supplement 5 3-10

Gröndahl C, Lessl M, Farge I, Hefele-Huartung C, Wassermann K and Otttesen IL (2000b) Meiosis activating sterol mediated resumption of meiosis in mouse oocytes in vitro is influenced by protein synthesis inhibition and cholera toxin Biology of Reproduction 62 775-780

Gutierrez CG, Campbell BK and Webb R (1997) Development of a long-term bovine granulosa cell culture system: induction and maintenance of estradiol production response to FSH and morphological characteristics Biology of Reproduction 56 608-616

Gutierrez CG, Ralph JH, Telfer E, Wilmut I and Webb R (2000) Growth and antrum formation of bovine preantral follicles in long-term culture in vitro. Biology of Reproduction $\mathbf{6 2}$ 1332-1338

Hartshorne GM (1997) In vitro culture of ovarian follicles Reviews of Reproduction 2 94-104

Hartshorne GM, Sargent IL and Barlow DH (1994) Meiotic progression of mouse oocytes throughout follicle growth and ovulation in vitro. Human Reproduction 9 352-359

Hovatta $\mathrm{O}$, Wright $\mathrm{C}$, Krausz T, Hardy $\mathrm{K}$ and Winston RML (1999) Human primordial, primary and secondary ovarian follicles in long-term culture: effect 
ở partial isolation Human Reproduction 142519 2524

Hsu SY, Kubo M, Chun S-Y, Haluska FG, Housman DE and Hsueh AJW (I995) Wilms tumor protein WTI as an ovarian transcription factor: decreases in expression during follicle development and repression of inhibin-a gene promoter Molecular Endocrinology 9 1356-1366

Huang E, Manova K, Packer A, Sanchez S, Bachvarova R and Besmer $\mathbf{P}$ (1993) The murine steel panda mutation affects kit ligand expression and growth of early ovarian follicles Developmental Biology 157 100109

Huntriss J, Gosden R, Hinkins M, Oliver B, Miller D, Rutherford A and Picton $\mathbf{H}$ (2002) Isolation, characterisation, and expression of the human factor in the germline alpha (FIGLA) in ovarian follicles and oocyles Molecular Human Reproduction $\mathbf{8}$ $1087-1095$

Hyttel P, Callesen H and Greve T (1997) Oocyte growth, capacilation and final maturation in cattle Theriogenology 47 23-32

Kito S and Bavister BD (1997) Maturation of hamster oocytes under chemically defined conditions and sperm penetration through the zona pellucida Zygote 4 199-210

Kotsuji F, Kubo M and Tominaga A (1994) Effect of interactions between granulosa and theca cells on meiotic arrest in bovine oocytes Journal of Reproduction and Fertility 100 151-156

McGrath SA, Esquela AF and Lee S-J (1995) Oocytespecific expression of growth/differentiation factor 9 Molecular Endocrinology 9 131-136

McNatty KP, Heath DA, Lundy T, Fidler AE, Quirke L, $\mathrm{O}^{\prime}$ Connell A, Smith P, Groome $\mathrm{N}$ and Tisdall DJ (1999) Control of early ovarian follicular development Journal of Reproduction and Fertility Supplement 49 123-135

Mertineit C, Yoder JA, Taketo T, Laird DW and Trasler JM (1998) Sex-specific exons control DNA melhyltransferase in mammalian germ cells development $125889-897$

Mhawi AJ, Kanka J and Motlik J (1991) Follicle and oocyte growth in early postnalal calves: cylochemical, autoradiographical and electron microscopical studies Reproduction. Nutrition and Development 31 115-126

Moor RM, Dai Y, Lee C and Fulka J (1998) Oocyte maturation and embryonic failure Human Reproduction Update 4 223-236

Nayudu PL and Osborn SM (1992) Factors influencing the rate of preantral and antral growth of mouse ovarian follicles in vitro. Journal of Reproduction and Fertility 95 349-362

Newton H, Picton HM and Gosden RG (1999) In vitro growth of oocyte-granulosa cell complexes isolated from cryopreserved ovine tissue Journal of Reproduction and Fertility 115 141-150
Obata Y, Kono T and Hatada I (2002) Maturation of mouse fetal germ cells in vitro. Nature $418497-498$

Oktay K, Briggs D and Gosden RG (1997a) Ontōgeny of follicle stimulating hormone receptor gene expression in isolated human ovarian follicles Journal of Clinical Endocrinolology and Metabolism $823748-$ 3751

Otsuka F, Moore RK, lemura S, Ueno $\mathrm{N}$ and Shimasaki S (2001) Follistatin inhibits the function of the oocytederived factor BMP-15 Biochemical and Biophysical Research Communication 289 961-966

Picton HM (2001) Activation of follicle development; the primordial follicle Theriogenology $\mathbf{5 5} 1193-$ 1210

Picton HM (2002) Docyte maturation in vitro. Current Opinions in Obstetrics and Gynaecology 14 295302

Picton HM, Briggs D and Gosden RG (1998) The molecular basis of oocyte growth and development Molecular and Cellular Endocrinology $14527-37$

Picton HM, Campbell BK and Hunter MG (1999a) Maintenance of oestradiol production and cytochrome $\mathrm{P} 450$ aromatase enzyme messenger ribonucleic acid expression in long-term serum-free cultures of porcine granulosa cells Journal of Reproduction and Fertility $115 \quad 67-77$

Picton HM, Mkandla A, Salha O, Wynn P and Gosden RG (1999b) Initiation of human primordial follicle growth in vitro in ultra-thin slices of ovarian cortex Human Reproduction 13 0-020

Picton HM, Jenner LJ and Kessopoulou E (2000a) Investigation of the impact of in vitro maturation and cryopreservation on the composition of the human zona pellucida Human Reproduction Abstract Series 15

Picton HM, Kim SS and Gosden RG (2000b) Cryopreservation of gonadal tissue and cells British Medical Bulletin 56 603-615

Qvist R, Blackwell LF, Bourne $\mathrm{H}$ and Brown IB (1990) Development of mouse ovarian follicles from primary to preovulatory stages in vitro. Journal of Reproduction and Fertility 89 169-180

Richard FJ and Sirard MA (1996) Effects of follicular cells on oocyte maturation. 11: theca cell inhibition of bovine oocyte maturation in vitro, Biology of Reproduction 54 22-28

Rose UM, Hanssen RG and Kloosterboer HJ (1999) Development and characterisation of an in vitro ovulation model using mouse ovarian follicles Biology of Reproduction 61 503-511

Roy SK and Treacy B] (1993) Isolation and long-term culture of human pre-antral follicles Fertility and Sterility 59 783-790

Schramm RD and Bavister BD (1994) Folliclestimulating hormone priming of rhesus monkeys enhances meiotic and developmental competence of oocyles matured in vitro. Biology of Reproduction 51 904-912 
Schroeder AC, Schultz RM, Kopf GS, Tayler FR, Becker RB and Eppig J (1990) Fetuin inhibits zona pellucida and conversion of ZP2 to ZP2 $f$ during spontanous mouse oocyte maturation in vitro in the absence of serum Biology of Reproduction 43 891-897

Shimasaki S, Zachow RJ, Li D, Kim H, lemura S-I, Ueno N, Sampath K, Chang RJ and Erickson GF (1999) A functional bone morphogenic protein system in the ovary Proceedings National Academy of Science USA $967282-7287$

Spears N, Boland NI, Murray AA and Gosden RG (1994) Mouse oocytes derived from in vitro grown primary ovarian follicles are fertile Human Reproduction 9 $527-532$

Spears N, Murray AA, Allison V, Boland NI and Gosden RG (1998) Role of gonadotrophins and steroids in the development of mouse follicles in vitro. Journal of Reproduction and Fertility 113 19-26

Tay II, Rutherford AJ, Killick SR, Maguiness SD, Partridge RJ and Leese HJ (1997) Human tubal fluid: production, nutrient composition and response to adrenergic agents Human Reproduction 12 24512456

van Wagtendonk-de Leeuw AM, Mullaart E, de Roos APW, Merton JS, den Daas JHG, Kemp B and de Ruigh L (2000) Effects of different reproductive techniques: Al, MOET or IVP on health and welfare of bovine offspring Theriogenology 53 575-597

Wandji S-A, Pelletier G and Sirard M-A (1992) Ontogeny and cellular localization of 125 -labelled follicle stimulating hormone and ${ }^{125}$-labelled human chorionic gonadotrophin binding sites in ovaries from bovine fetuses and neonatal calves Biology of Reproduction 47 814-822

Wandji SA, Eppig JI and Fortune IE (1996a) FSH and growth factors affect growth and endocrine function in vitro of granulosa cells of bovine preantral follicle Theriogenology 45 817-832

Wandji S-A, Srsen V, Voss AK, Eppig IJ and Fortune IE (1996b) Initiation in vitro of growth of bovine primordial follicles Biology of Reproduction $\mathbf{5 5}$ 942-948

Wright $C$, Hovatta $O$, Margara $R$, Trowe G, Winston RML, Franks S and Hardy K (1999) Effect of follicle stimulating hormone and serum substitution on the development and growth of early human follicles Human Reproduction 14 1555-1562

Wynn P, Picton HM, Krapez JA, Rutheford Al, Balen AH and Gosden RG (1998) FSH pre-treatment promotes the numbers of human oocytes reaching metaphase II by in vitro maturation Human Reproduction 13 3132-3138

Young LE and Fairburn HR (2000) Improving the safety of embryo technologies: possible role of genomic imprinting Theriogenology 53 627-648

Young LE, Sinclaire KD and Wilmut I (1998) Large offspring syndrome in cattle and sheep Reviews of Reproduction 3 155-163

Zhang X, Rutledge J and Armstrong DT (1991) Studies on zona hardening in rat oocytes that are matured in vitro in a serum-free medium Molecular Reproduction and Development 28 292-296 